\title{
Relationships of Anthropometric Indices of Centripetal Adiposity With Essential Hypertension and Type - 2 Diabetes Mellitus in Kano Metropolis
}

\author{
*A.Y. Asuku, L. H. Adamu, I. A. Tela, A. Gudaji and S. Datti \\ Department of Anatomy, Faculty of Basic Medical Sciences, College of Health Sciences, Bayero University, Kano, P.M.B. 3011, \\ Nigeria
}

[Corresponding Author: E-mail: abdullahiyusufasuku@gmail.com; C:+2348032878100]

\section{ABSTRACT}

The use of centripetal indices of adiposity for cardiovascular risk prediction is gaining popularity over body mass index (BMI). This study seeks to investigate the relationships of centripetal adiposity indices with essential hypertension and type 2 diabetes mellitus and find sexual dimorphism in such relationship in Kano. It also investigates the correlation between centripetal adiposity indices and BMI. The study included 405 registered hypertensive, diabetic or hypertensive - diabetic subjects (215 females and 190 males) with mean age of $53.4 \pm 0.36$. The adiposity indices [BMI, waist circumference (WC) hip circumference (HC) and waist to hip ratio (WHR)] were obtained using standard protocol. Chi-square and Pearson correlation were used to test for the relationship as described. The results showed that WC was not significantly associated $(p>0.05)$ with essential hypertension and type 2 diabetes mellitus in females, but was significant in males ( $P$ $=0.04)$. In both sexes, WHR was significantly associated with essential hypertension and type 2 diabetes mellitus. However, a stronger relationship was observed in males $(P<0.0001)$. Where both WC and WHR correlated positively with essential hypertension and type 2 diabetes mellitus in males, the relationship was stronger for WHR $(P<0.0001)$ compared to WC $(P=0.04)$. In conclusion, WHR in both sexes had significant association with essential hypertension and type 2 diabetes mellitus while WC in males correlated strongly with BMI compared to WHR.

Keywords: Centripetal adiposity, essential hypertension, type 2 diabetes mellitus, Sexual dimorphism.

\section{INTRODUCTION}

The adverse metabolic and cardiovascular consequence of excessive body fat accumulation is well documented in the literature (Deurenberg et al., 1998; Reilly, 2010). For many years, the body mass index obtained by dividing an individual's weight with the square of the height has been used as a tool for estimating total body fat collection and thus an indirect means of cardiovascular and metabolic risk estimation (Caballero, 2007). Pathologically, the relationship between body adiposity with hypertension and diabetes is closely linked with insulin resistance which is a major marker in the pathogenesis of metabolic syndrome (Flegal et al., 2012). Although, the BMI otherwise known as the Quetelet index is reported to be reliable in about $90 \%$ of individuals, its inaccuracy in certain group of individuals such as athletes and mesomorphs whose increased weights are rather accounted for by skeletal muscle hypertrophy is well documented (Deurenberg et al., 1998).

Racial discrepancy in the sensitivity of the Quetelet index and the fact that it doesn't take into account regional body fat distribution has reduced the reliability on BMI as an anthropometric tool for cardiovascular risk estimation (Tulloch-Reid et al., 2003). This has triggered the interest to explore other reliable anthropometric methods of estimating adiposity such as central or centripetal adiposity indices [waist circumference (WC), hip circumference $(\mathrm{HC})$, waist-hip-ratio (WHR) neck circumference (NC)]; four standard skin thickness measurements (subscapular, triceps, biceps, supra-iliac), etc. Of these methods, WC, HC and WHR are considered to be more strongly associated with adiposity related metabolic disorders (Chee-Eng, 2004). However, there still exist population and ethnic specific variations in 
the strength of relationship of these adiposity indices with hypertension and diabetes.

There currently exist population specific normal reference values for these indices (Tulloch-Reid et al., 2003). The emphasis on central indices of adiposity became popular in the early 1980s when it was discovered some individuals with normal BMl but harboring excessive abdominal fat had relatively higher incidences of cardiovascular events. It was then construed that the key to obesity is body fat rather than body weight (Alberti et al., 2005). Overall, the documented racial and ethnic discrepancies (Tulloch-Reid et al., 2003) in body adiposity measures and variation in their strength of relationship with hypertension and diabetes provide the rationale for this study. This is in keeping with the current global recommendation of finding ethnic specific adiposity tool that is most germane to each population in view of identifying the most dependable index of centripetal adiposity in risk prediction for essential hypertension (HTN) and Type 2 diabetes mellitus (T2DM). The aim of this study was to investigate the relationships of centripetal adiposity indices with essential hypertension and type - 2 diabetes mellitus and find sexual dimorphism in such relationships.

\section{MATERIALS AND METHODS}

\section{Study location and Experimental Subjects}

This study was carried out on the patients attending hypertensive and diabetic clinic of Murtala Muhammad Hospital, Kano. Systematic random sampling technique was employed in selecting 405 subjects. The subjects included 190 male and 215 female hypertensive, diabetic or hypertensive-diabetic patients registered in the hospital and diagnosed to have these complications. As inclusion criteria, the study considered consenting subjects in the aged 4065 years, indigenes of Kano State, Nigeria and were neither pregnant nor having abdominal or pelvic space occupying lesions, congenital or acquired spinal deformity. Ethical approval was obtained from Kano state hospitals management board and written informed consent obtained from the subjects.

\section{Collection of bio-data and medical history}

A profoma was used to access the following data: patient file number, sex, age, ethnicity, location of birth, and medical history. The subjects were then categorized into hypertensive, diabetic and hypertensive-diabetics.

\section{Anthropometry}

Each patient was confidentially examined using a mobile hospital screen cover. Height was measured to the nearest $0.1 \mathrm{~cm}$ as the vertical distance between the standing surface and the vertex of the head while the subject was standing erect without shoes using a stadiometer (Price et al., 2006). The weight was measured in kilograms using a digital weighing scale while the subject is in light clothing. The body mass index was be calculated using the formula:

BMI $\left(\mathrm{Kg} / \mathrm{m}^{2}\right)=\frac{w t}{H^{2}}$

Where wt =weight; $\mathrm{H}=$ height (Mueler et al., 1991; WHO, 1995).

Waist circumference was measured in centimeters with a non- stretchable plastic tape horizontally placed over the unclothed abdomen at the narrowest point between the lowest rib and the iliac crest (Lean et al., 1995). The hip circumference was measured while the subject was standing erect with the feet fairly close together. The measuring tape was passed around the point with the maximum circumference over the buttocks (Lean et al., 1995; Heish and Yoshinaga., 1999). WC was divided by the $\mathrm{HC}$ to obtain waist-hip ratio (WHR).

The centripetal obesity indices were categorized as "normal" or "abnormal" based on the National Cholesterol Education Program (NCEP) reference values. The WC was considered normal when it is $<102 \mathrm{~cm}$ in males and $<88 \mathrm{~cm}$ in female, whereas the WHR was considered 
normal at $<0.9$ in males and $<0.85$ in females (NCEP, 2002).

\section{Statistical analyses}

The data were expressed as mean \pm standard deviations of the samples. Chi-square was used to test the relationship between the occurrence of the diseases (hypertension, diabetes or their co morbidity) with BMl and centripetal adiposity indices (WC, HC and WHR). Pearson's correlation was used to find the relationship between the central obesity indices and BMI. SPSS version 20 was used for statistical analyses and $p<0.05$ was set as level of significance.

\section{RESULTS}

The mean age of subjects was 53.39 years. The minimum age was 36years while the maximum was 69 years with standard error of 0.36 . The mean height was $163.36 \mathrm{~cm}$, the minimum and maximum height of the subjects were $141.8 \mathrm{~cm}$ and $189.1 \mathrm{~cm}$ respectively with standard error of 0.44 . The mean for the subjects' weight was $69.44 \mathrm{~kg}$, which ranged from $41.3 \mathrm{~kg}-112 \mathrm{~kg}$ (standard error of 0.65). The calculated body mass index had a mean of 26.06, ranging from 17.21- of 43.7 (standard error 0.24). The waist circumference and waist- to- hip ratio had mean values of $91.88 \mathrm{~cm}$ and 0.96 respectively. The maximum waist circumference was $118.7 \mathrm{~cm}$ and minimum was 65.9 with a standard error of 0.58 . Waist to hip ratio had maximum of 1.14 , a minimum of 0.10 and a standard error of 0.0001 (Table 1).

Table 1: Age and Anthropometric measurements of subjects

\begin{tabular}{llllll}
\hline Variables & Mean & Minimum & Maximum & Range & SEM \\
\hline Age (years) & 53.39 & 36.00 & 69.00 & 33.00 & 0.36 \\
Weight $(\mathrm{kg})$ & 69.44 & 41.30 & 112.00 & 70.70 & 0.65 \\
Height $(\mathrm{cm})$ & 163.36 & 141.80 & 189.10 & 47.30 & 0.44 \\
BMl $\left(\mathrm{kg} / \mathrm{m}^{2}\right)$ & 26.06 & 17.21 & 43.70 & 26.49 & 0.24 \\
WC $(\mathrm{cm})$ & 91.88 & 65.90 & 118.70 & 52.80 & 0.58 \\
WHR & 0.96 & 0.10 & 1.14 & 1.04 & 0.0001 \\
\hline
\end{tabular}

BMI: body mass index, WC; waist circumference, WHR; waist to hip ratio, SEM; standard error of mean

Table 2 presents the relationships between indices of centripetal adiposity with essential hypertension and type 2 diabetes of recruited subjects. It was observed that there was statistically significant association $(p=0.04)$ between WC with hypertension and/ or diabetes in male participants. Table 3 shows that there was no statistically significant relationship $(p=$ 0.07) between WC with hypertension and/ or diabetes in female participants. As presented in Table 4, a statistically significant relationship $(p<0.05)$ was observed between WHR and hypertension and/ or diabetes in male participants. Table 5 shows that there was statistically significant relationship $(p=0.023)$ between WHR with hypertension and/ or diabetes in female participants.
In both males and females, BMI correlated strongly with the waist circumference among hypertensive and diabetic patients. However BMI did not correlate strongly with WHR in all the medical cases. Also, BMI correlated strongly with $W C$ in female patients but weakly in male patient with co-morbidities. Table 6 shows that in hypertensive, diabetic and hypertensive-diabetic subgroups, BMI correlated positively and significantly with WC and WHR except in males who are hypertensive $(r=0.181)$, female diabetic patients $(r=0.257)$. It was also observed that in the co-morbidity group BMl did not show significant correlation with WHR. 
Nigerian Journal of Basic and Applied Science (June, 2017), 25(1): 32-39

Table 2: Relationship of waist circumferences (WC) with patient medical history in males

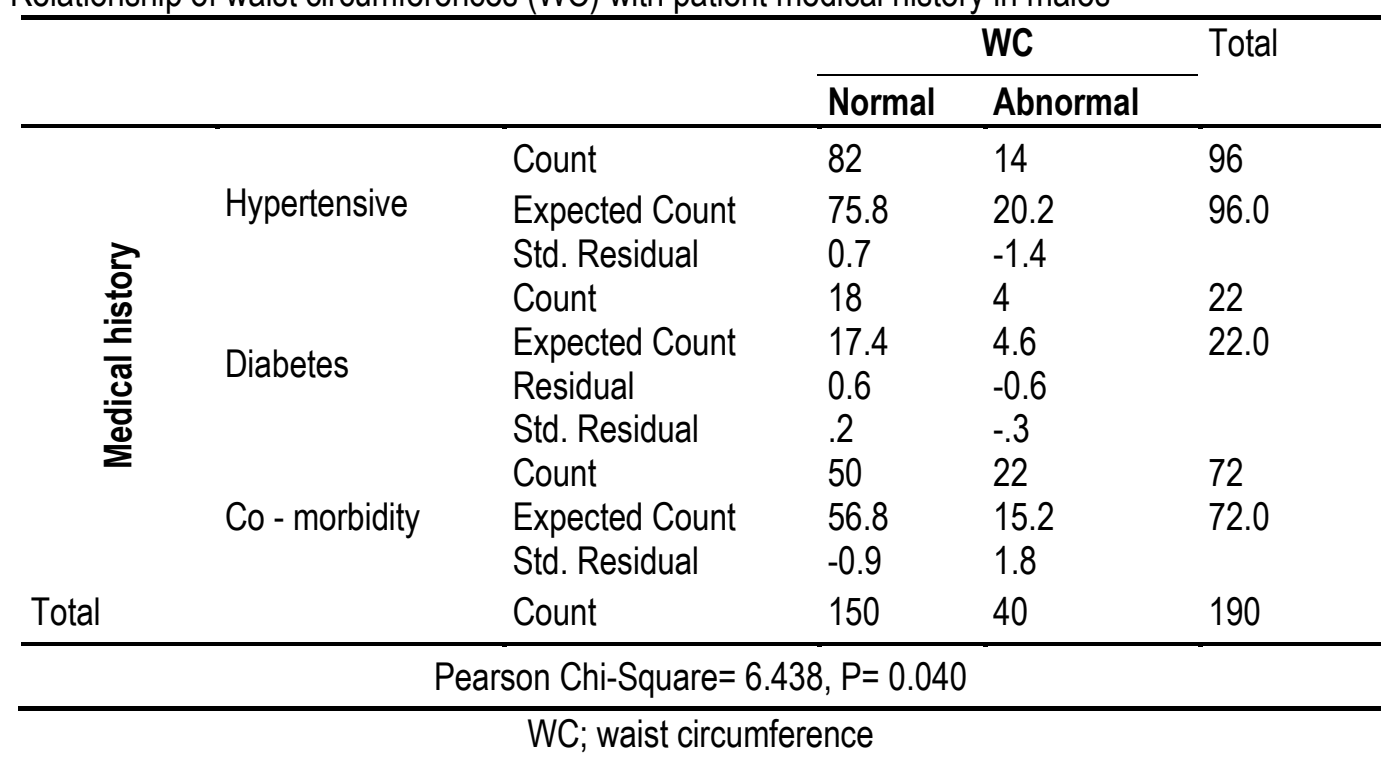

Table 3: Relationship of waist circumferences (WC) with patient medical history in females

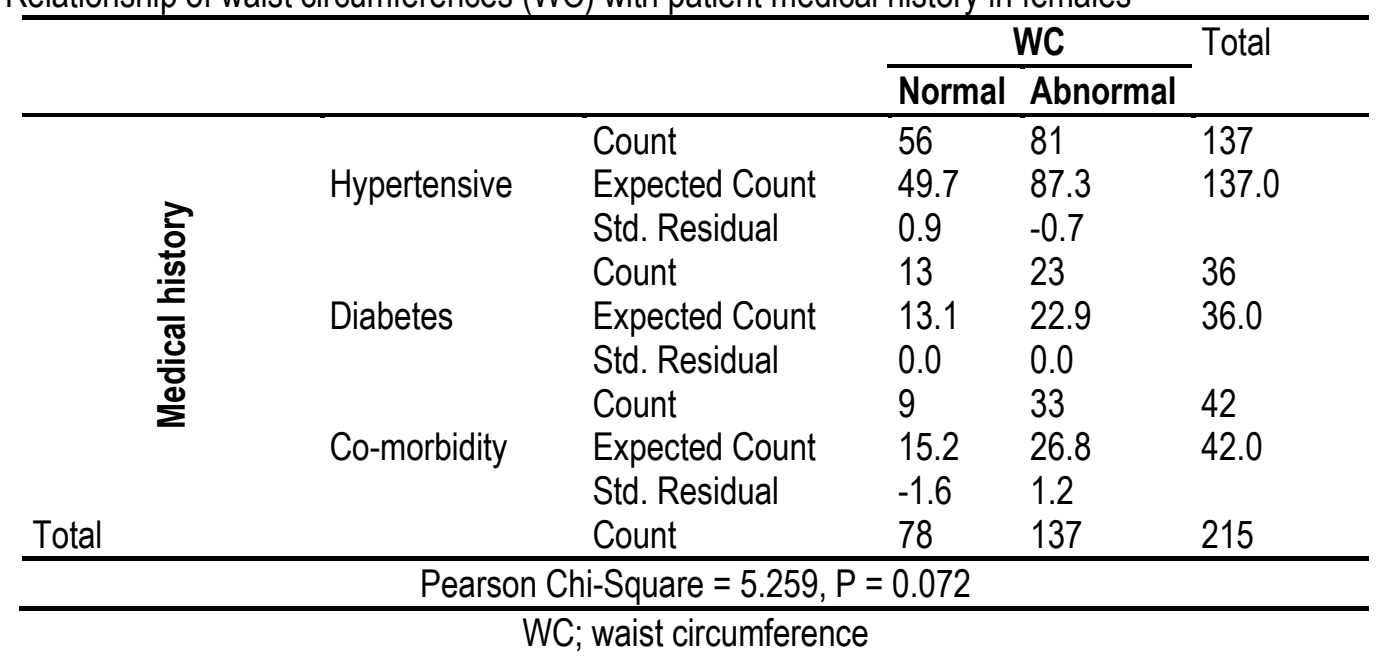

Table 4: WHR and patient medical history relationship in males

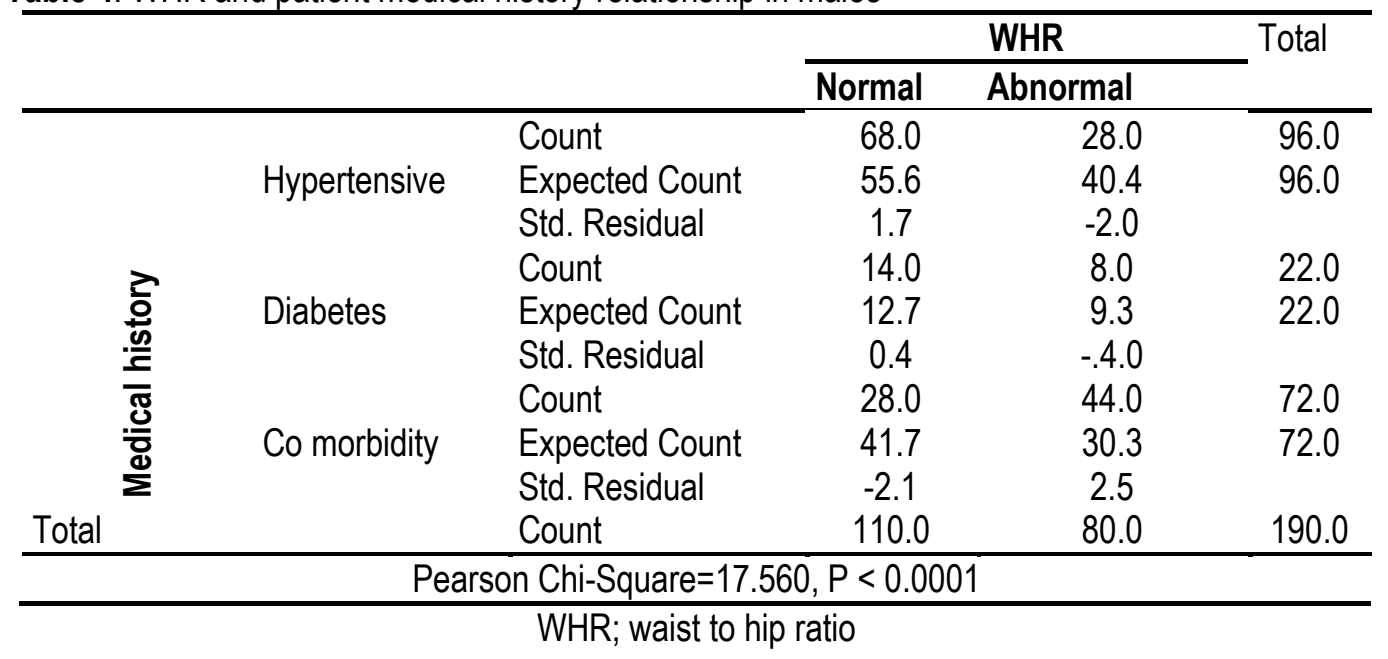


Table 5: WHR with patient medical history relationship in females

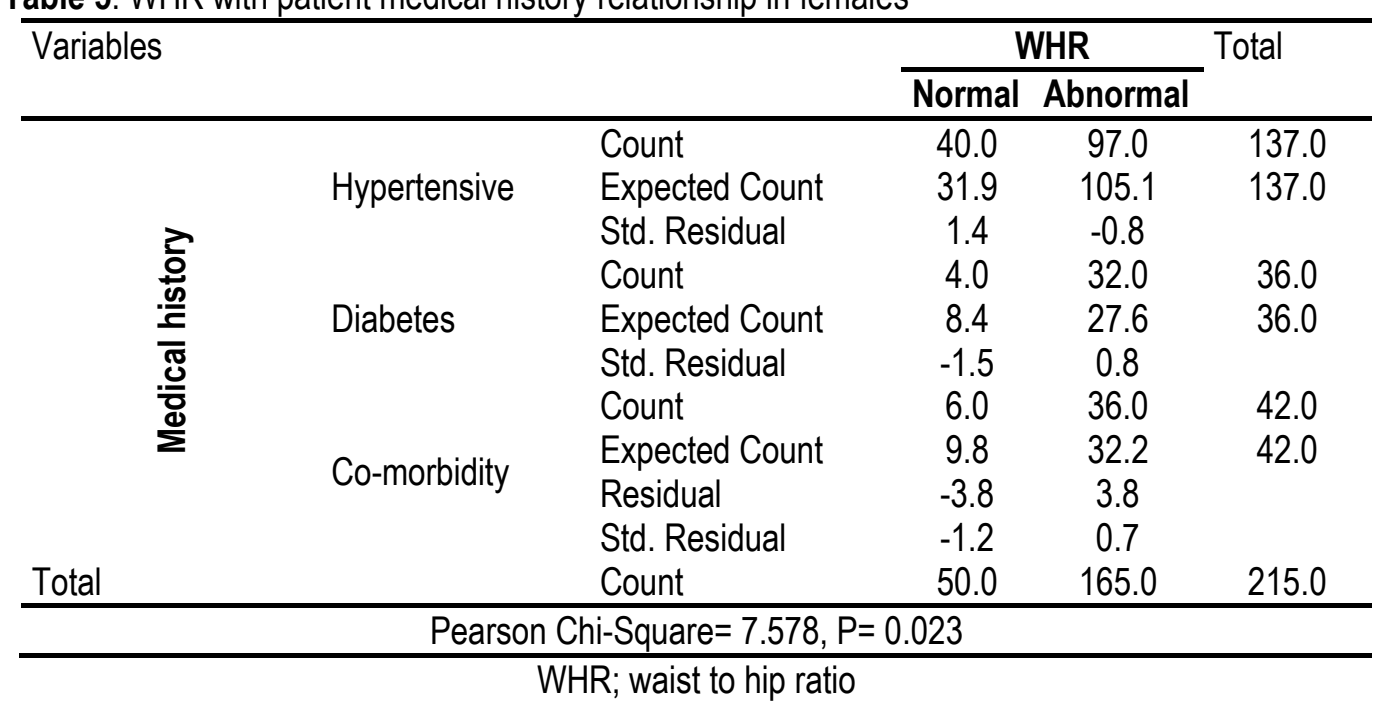

Table 6: Relationship between BMI and centripetal adiposity indices in patients with essential hypertension, type 2 diabetes mellitus and co-morbidity

\begin{tabular}{|c|c|c|c|c|}
\hline Medical history & Sex & Variables & $W C$ & WHR \\
\hline \multirow[t]{4}{*}{ Hypertensive } & Female $(n=137)$ & $\mathrm{BMI}\left(\mathrm{kg} / \mathrm{m}^{2}\right)$ & $0.778^{* *}$ & $0.365^{* \star}$ \\
\hline & & WC & & $0.688^{* *}$ \\
\hline & Male $(n=96)$ & $\mathrm{BMI}\left(\mathrm{kg} / \mathrm{m}^{2}\right)$ & $0.776^{* *}$ & 0.181 \\
\hline & & WC & & $0.266^{* *}$ \\
\hline \multirow[t]{4}{*}{ Diabetes } & Female $(n=36)$ & $\mathrm{BMI}\left(\mathrm{kg} / \mathrm{m}^{2}\right)$ & $0.700^{* *}$ & 0.257 \\
\hline & & WC & & $0.630^{* *}$ \\
\hline & Male $(n=22)$ & $\mathrm{BMI}\left(\mathrm{kg} / \mathrm{m}^{2}\right)$ & $0.707^{* *}$ & $0.428^{*}$ \\
\hline & & WC & & $0.692^{* *}$ \\
\hline \multirow[t]{4}{*}{ Co-morbidity } & Female $(n=42)$ & $\mathrm{BMI}\left(\mathrm{kg} / \mathrm{m}^{2}\right)$ & $0.796^{* *}$ & 0.099 \\
\hline & & WC & & $0.313^{*}$ \\
\hline & Male $(n=72)$ & $\mathrm{BMI}\left(\mathrm{kg} / \mathrm{m}^{2}\right)$ & $0.488^{* *}$ & 0.152 \\
\hline & & WC & & $0.563^{* *}$ \\
\hline
\end{tabular}

\section{DISCUSSION}

The statistically significant relationship between waist circumferences of male subjects (Table 2), waist-hip-ratio of the male subjects (Table 4), and waist-hip-ratio of the female subjects (Table 5) with essential hypertension and type 2 diabetes mellitus are in keeping with the findings of Dagenais et al. (2005) who followed nearly 8,000 subjects over the course of 4.5 years and reported that although the upper percentiles of $\mathrm{BMI}, \mathrm{WC}$, and WHR were all associated with increased relative risk for cardiovascular events, the magnitude of the relationship was greater for WC and WHR. Also Zhang et al. (2014) followed more than 29,000 men during a period of 3 years and reported WHR as a stronger predictor of risk of hypertension and diabetes compared with BMI

A study conducted to assess abdominal Adiposity and Clustering of multiple metabolic syndromes in White, Black and Hispanic Americans WC appears to be a marker for multiple metabolic syndromes in these ethnic groups. The results of this investigation lend support to the view that waist measurement should be considered as a clinical variable for assessing the risk of cardiovascular diseases (Ike et al., 2000). The relatively higher prevalence of diabetes or 


\section{Nigerian Journal of Basic and Applied Science (June, 2017), 25(1): 32-39}

hypertension among Indian-Asians who had similar anthropometric dimension and common socio-demographic characteristics with Indians elswhere was solely attributed to higher truncal obesity indices, suggesting a strong correlation between central obesity and cardiovascular disease (Shaw et al., 2010). Similarly, a cross sectional study conducted in Zaria, Northern Nigeria on the WC, BMI and its correlations with the blood pressure of a sample of women found that the waist circumference was a better measure in assessing obesity hence a marker for cardiovascular risks. In the same study, a significant positive correlation was found to exist between the waist indices and BMI (Achie et al., 2012).

On the contrary however, the present study observed no statistically significant relationship between the waist circumference in female subjects and the occurrence of hypertension and diabetes (Table 3). Probably, the WC known to correlate strongly with intra-abdominal visceral fat deposit (Elliot et al., 2000) and a common determinant of insulin resistance may not be the case for female subjects in this study. It could be (though not determined in this study) that the values of waist circumference obtained for the females may be due to laxity of the anterior abdominal wall muscles rather than intraabdominal fat. The laxity of the anterior abdominal wall muscles is expected in this age group of the females recruited for the study (> 40years) due to likelihood of multiple deliveries, a common phenomenon in the cultural practices of the subjects under study.

Among the male participants where it was observed that both WC and WHR had significant relationship with essential hypertension and type 2 diabetes mellitus, the strength of relationship was stronger for WHR $(P<0.0001$ for WHR and $P=0.04$ for $W C$ ). Also for both sexes, though WHR had significant relationship with essential hypertension and type 2 diabetes mellitus, the strength of relationship was stronger for males. This underscores and singles out WHR as a more useful anthropometric screening tool for essential hypertension and type 2 diabetes mellitus in both sexes. This finding is similar to that of Dagenais et al., (2005) which showed WHR was independently associated with prevalence of essential hypertension and type 2 diabetes mellitus and provided better discrimination than either BMI or WC.

Wang et al. (2005) demonstrated that WHR is a stronger predictor of cardiovascular risk in both males and females. However findings of other researches in the subject area point towards WC as the novel central adiposity tool. For example a recent study assessed and compared the strength of relationship and discriminatory capability of measures of adiposity such as body mass index (BMI), waist circumference (WC), hip circumference $(\mathrm{HC})$, waist-hip-ratio (WHR), waist-height-ratio (WHtR) for prevalent screen detected diabetes (SDM) risk in a sub-Saharan African population, WC was shown to be the best predictor followed by WHtR of prevalent SDM in this population, while BMI and WHR were less effective (Mbanya et al., 2015). Differences in sex with respect to strength of relationship of WHR with essential hypertension and type 2 diabetes mellitus may be linked to the effect of multiple deliveries on WC in females, occupation and life style. Differences in the pattern of the relationship here observed compared to other studies may be explained by environmental and genetic differences peculiar to different population studied. To explain this further, there is currently an ongoing controversy on the specific measure of centripetal adiposity that carries the greatest cardio-metabolic risk citing conflicting reports from different races and ethnic groups, genetic makeup, diets and socio-dermographic characteristics. These factors could equally explain the differences in the observed WC and WHR as measures of adiposity Based on our findings, we speculate strongly that the laxity of the anterior abdominal wall muscles associated with gestation and the attendant increase in the WC may have influenced observations for WC in the female subjects. 


\section{CONCLUSION}

The relationship between the indices of centripetal adiposity with essential hypertension and type 2 diabetes mellitus in selected subjects resident in Kano metropolis showed a sexual dimorphism in the pattern and strength of the relationship. While WC in females had no significant relationship with essential hypertension and type 2 diabetes mellitus, this relationship however was significant in males.WHR was generally significantly associated with the diseases in both sexes, with the strength of relationship stronger in males.

ACKNOWLEDGMENT: We will like to acknowledge the management of Murtala Muhammad Specialist hospital, especially hypertension and diabetic clinic for their support during the data collection exercise.

\section{REFERENCE}

Achie, L.N., Olorunshola, K.V., Toryila, J.E. and Tende, J.A.( 2012). The Body Mass Index, Waist Circumference and Blood Pressure of Postmenopausal Women in Zaria, Northern Nigeria. Current Research journal of Biological Sciences 4(3): 329-332.

Alberti, K.G., Zimmet, P. and Shaw, J. ( 2005) The metabolic syndrome. A new world wide definition. Lancet 366:1059-62.

Caballero, B (2007). "The global epidemic of obesity: An overview". Epidemiological Review 29: 1-5.

Chee-Eng, T., Stephan, M., Daniel, W., Suok-Kai, C.and E-Shyong, T. (2004). Can we apply the national cholesterol education program adult treatment panel definition of the metabolic syndrome to Asians? Diabetes Care 27:1182-6.

Dagenais G.R., Yi, Q., Mann, J.F.( 2005). Prognostic impact of body weight and abdominal obesity in women and men with cardiovascular disease. America Heart Journal 149:54-60.

Deurenberg P, Yap M, Van Staveren, .WA. ( 1998). Body mass index and percentage body fat: a meta analysis among different ethnic groups. International Journal of Obesity and Related Metabolic Disorder 22:1164-71.

Elliott, S., Nancy, L. K., Judith, S.S., Karen, T. and Peter, J. H (2002). Fructose, weight gain, and the insulin resistance syndrome. American Journal of Clinical Nutrition 76 (5): 911-922.

Flegal, K.M., Carrol, M.D., Kit, B.K., Ogden CL (2012). Prevalence of obesity and trends in the distribution of body mass index among US adults, 1999-2010. Journal of American Medical Association. 307(5):491-7.

Ford, E.S., Mokdad, A.H., Giles, W.H.( 2003) Trends in waist circumference among U.S. adults. Obesity Research 11:12231231.

Heish, S.D. and Yoshinaga, H. (1999). Do people with similar waist circumference share similar health risks irrespective of height? Tohoku Journal Experimental Medicine 188:55-60

Ike, O.,Youlian, L., Charles, N. R., Elaine, P., And Richard, S.( 2000) Abdominal Adiposity and Clustering of Multiple Metabolic Syndrome in White, Black and Hispanic Americans. Annal of epidemiology 10:263-270

Lean, M.E., Han, T.S., Morrison, C.E (1995). Waist circumference as a measure for indicating need for weight management. British Medical Journal 311(6998):158-61

Marno, C.R., Helke, M.F., Fahim, A. (2008) Comparism of waist circumference versus body mass index in diagnosing metabolic syndrome. American journal of cardiology 102:40-46

Mbanya , V.N., Kengne , A.P., Mbanya., J.C, Akhtar, H.( 2015) Body mass index, waist circumference, hip circumference, waisthip-ratio and waist-height-ratio: Which is the better discriminator of prevalent screen-detected diabetes in a Cameroonian population? Diabetes 


\section{Nigerian Journal of Basic and Applied Science (June, 2017), 25(1): 32-39}

Research and Clinical Practice DIAB6291: 8

Mueller, W.H., Wear, M.L., Hanis, C.L., Emerson, J.B., Barton, S.A., Hewett-Emmett, D. (1991). Which measure of body fat distribution is best for epidemiologic research? American Journal of Epidemiology, 133: 858-869.

NCEP (National Cholesterol Education Program) (2002). Third Report of the Expert Panel on Detection, Evaluation, and Treatment of High Blood Cholesterol in Adults (ATP III Final Report). National Institutes of Health. p. 11-17.

Price, G.M., Uauy, R., Breeze, E., Bulpitt, C.J., Fletcher, A.E (2006). Weight, shape, and mortality risk in older persons: elevated waist-hip ratio, not high body mass index, is associated with a greater risk of death. American Journal of Clinical Nutrition, 84(2):449-60

Reilly, J.J. (2010). Assessment of obesity in children and adolescents: synthesis of recent systematic reviews and clinical guidelines. Journal of Human Nutrition and Diet, 23: 205
Shaw, J.E., Sicree, R.A., Zimmet, P.Z (2010). Global estimates of the prevalence of diabetes for 2010 and 2030. Diabetes Research and Clinical Practice, 87:4-14

Tulloch-Reid, M.K., Williams, D.E., Looker, H.C., Hanson, R.L, Knowler, W.C, (2003).Do measures of body fat distribution provide information on the risk of type 2 diabetes in addition to measures of general obesity? Comparison of anthropometric predictors of type 2 diabetes in Pima Indians. Diabetes Care, 26: 2556-2561

Wang, Y., Rimm, E.B., Stampfer, M.J., Willett, W.C, Hu, F.B. (2005) Comparison of abdominal adiposity and overall obesity in predicting risk of type 2 diabetes among men. American Journal Clinical Nutition, 81:555-563.

World Health Organization (1995). WHO expert Committee. Physical status: the use and interpretation of anthropometry. Geneva Report, 12:18

Zhang ZQ, Liu YH, Xu Y, Dai XW, Ling WH, Su YX, (2014). The validity of the Body Adiposity Index in predicting percentage body fat and cardiovascular risk factors among Chinese.Clinical Endocrinolog, 18 (3): $356-362$ 